\title{
Impacting patient-centred outcomes in COPD: breathlessness and exercise
} tolerance

\author{
D.E. O’Donnell
}

ABSTRACT: The physiological hallmark of chronic obstructive pulmonary disease (COPD) is expiratory flow limitation. However, it is the resultant air trapping and associated increases in lung volume (hyperinflation) that provide a mechanistic link between the physiological impairment and the characteristic symptoms of COPD, such as dyspnoea (breathlessness), exercise intolerance and reduced health-related quality of life (HRQOL).

During exercise, the negative consequences of hyperinflation are particularly apparent. Delayed lung emptying and increased end-expiratory lung volume are aggravated, and tidal volume cannot rise to meet the increased ventilatory demands. Dyspnoea intensity rises abruptly to intolerable levels, and further increases in ventilation can only be achieved by rapid breathing. This rebounds to cause greater hyperinflation in a vicious cycle. As a result, patients with COPD often prematurely stop or avoid activity, leading to deconditioning, increased dyspnoea, worsening of disease and, ultimately, reduced HRQoL.

The Global Initiative for Chronic Obstructive Lung Disease guidelines recommend long-acting bronchodilators as first-line maintenance treatment in COPD.

Once-daily tiotropium $18 \mu \mathrm{g}$, a long-acting anticholinergic agent with 24-h efficacy, has been consistently shown to relieve dyspnoea and improve exercise tolerance and health status. These improvements may allow patients with chronic obstructive pulmonary disease to increase their daily activities, thereby reversing the cycle of chronic inactivity and muscle deconditioning.

KEYWORDS: Bronchodilators, chronic obstructive pulmonary disease, dyspnoea, exercise tolerance

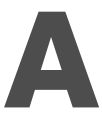

lthough expiratory flow limitation is the primary physiological hallmark of chronic obstructive pulmonary disease (COPD), dyspnoea (or breathlessness) and the inability to engage in the usual activities of daily living are the most distressing symptoms for patients with the disease. Progressive dyspnoea and the reduction in daily activities collectively contribute to the gradual deterioration of the patient's health-related quality of life (HRQoL). Therefore, from the patient's perspective, symptom improvement and the ability to increase or resume daily activities are desirable treatment goals. In agreement with this, the Global Initiative for Chronic Obstructive Lung Disease (GOLD) guidelines state that effective management should aim to relieve symptoms such as dyspnoea, as well as improve exercise tolerance and HRQoL [1].

The aim of the present article is to describe the physiological mechanisms by which expiratory flow limitation, and consequent trapping of air in the lungs, leads to dyspnoea and reduced exercise tolerance in patients with COPD, with a view to explaining how bronchodilators may relieve symptoms. In addition, the efficacy of long-acting bronchodilators in improving these patient-centred outcomes is evaluated.

\section{PATHOPHYSIOLOGY OF COPD}

In patients with COPD, pathological changes in the central airways, peripheral airways, lung parenchyma and pulmonary vasculature lead to physiological changes in lung function. In particular, the combined effects of reduced elastic lung recoil and increased airway resistance lead to a compromised ability to expel air during forced and quiet expiration. This is termed as expiratory flow limitation and is the physiological hallmark of COPD. Further, the rate of lung emptying, which is dictated by the product of compliance and resistance, is often substantially delayed in patients with COPD. Expiratory flow
CORRESPONDENCE

D.E. O'Donnell

Division of Respiratory and Critical Care Medicine

Respiratory Investigation Unit

Dept of Medicine

Queen's University

102 Stuart Street

Kingston

ON

K7L 2V6

Canada

Fax: 16135491459

E-mail: odonnell@post.queensu.ca

CONFLICT OF INTEREST STATEMENT D. O'Donnell has received honoraria from Boehringer Ingelheim (Toronto, ON, Canada) and Pfizer (Toronto) for his participation in clinical research, advisory board meetings and continuing medical education events. D. O'Donnell has no financial conflicts of interest or other relationship with a commercial entity in relation to this article. 
limitation and delayed lung emptying result in air trapping and lung hyperinflation, which is defined as an abnormal increase in end-expiratory lung volume (EELV; the volume of air remaining in the lungs at the end of spontaneous expiration).

The negative consequences of hyperinflation manifest during activity or any other circumstances leading to increased ventilatory demand. In healthy subjects, EELV and inspiratory capacity (IC) are maintained throughout exercise (fig. 1a). Thus, both the rate and depth (tidal volume $(V \mathrm{~T})$ ) of respiration are normally increased to accommodate the increased metabolic demand. However, in patients with COPD, the delayed lung emptying and increased EELV (hyperinflation) already present at rest are aggravated further during exercise, when there is even less time for adequate expiration (fig. 1b). This is termed dynamic hyperinflation ( $\mathrm{DH}$; the temporary and variable increase in EELV above its baseline value).

DH generally occurs early in exercise, as ventilation increases, and initially has favourable mechanical and sensory consequences. Thus, as $V \mathrm{~T}$ becomes positioned close to total lung capacity (TLC), the airways become stretched open and expiratory flow limitation is attenuated. However, these beneficial effects of DH soon become negated. DH markedly increases the tidal inspiratory pressure or effort required to generate an increase in $V \mathrm{~T}$ in patients with COPD compared with normal subjects [2]. In other words, in COPD patients, the relationship between inspiratory effort and $V \mathrm{~T}$ displacement (i.e. the effort:displacement ratio) becomes increasingly disparate as exercise proceeds because $V \mathrm{~T}$ becomes essentially fixed close to TLC. This increased effort:displacement ratio is thought to crudely reflect neuromechanical dissociation of the respiratory system. As the patient exercises, dyspnoea intensity rises abruptly to intolerable levels after a minimal inspiratory reserve volume (IRV) of $\sim 0.5 \mathrm{~L}$ below TLC. Further volume expansion is then impossible, despite strenuous inspiratory efforts, i.e. there is "no more room to breathe". Increases in ventilation can only be achieved by increasing breathing frequency, which rebounds to cause greater hyperinflation in a vicious cycle [2].

In several studies, correlations have been found between dynamic hyperinflation (EELV/TLC), neuromechanical dissociation (pressure/maximal inspiratory pressure ( $P$ I,max):VT/ vital capacity (VC) ratio) and dyspnoea (Borg score) at a standardised time during exercise in patients with COPD [26]. For example, in one study, the Borg score at a standardised oxygen demand $\left(V^{\prime} \mathrm{O}_{2}\right)$ during a symptom-limited incremental cycle ergometry test was strongly associated with pressure/ $P \mathrm{I}$,max:VT/VC ratio $(\mathrm{r}=0.86 ; \mathrm{p}<0.001)$ and EELV $/ \mathrm{TLC}(\mathrm{r}=0.69$; $\mathrm{p}<0.001)$ [2]. The pressure $/ P \mathrm{I}, \mathrm{max}: V \mathrm{~T} / \mathrm{VC}$ ratio was also strongly related to EELV/TLC at a standardised $V^{\prime} \mathrm{O}_{2}$ $(\mathrm{r}=0.78 ; \mathrm{p}<0.001)$. Understanding the associations between dynamic hyperinflation, neuromechanical dissociation and Borg dyspnoea provides a therapeutic target for COPD; expansion of $V \mathrm{~T}$ (by reducing EELV) for a given muscular effort should improve dyspnoea.

\section{EFFECT ON BRONCHODILATORS ON DYSPNOEA AND EXERCISE INTOLERANCE}

The GOLD guidelines recommend bronchodilators, such as $\beta_{2^{-}}$ agonists, anticholinergic agents and methylxanthines, for firstline symptom control, and long-acting bronchodilators for first-line maintenance treatment in COPD [1]. Bronchodilators, administered as inhaled therapy on an as-needed basis or on a

a)

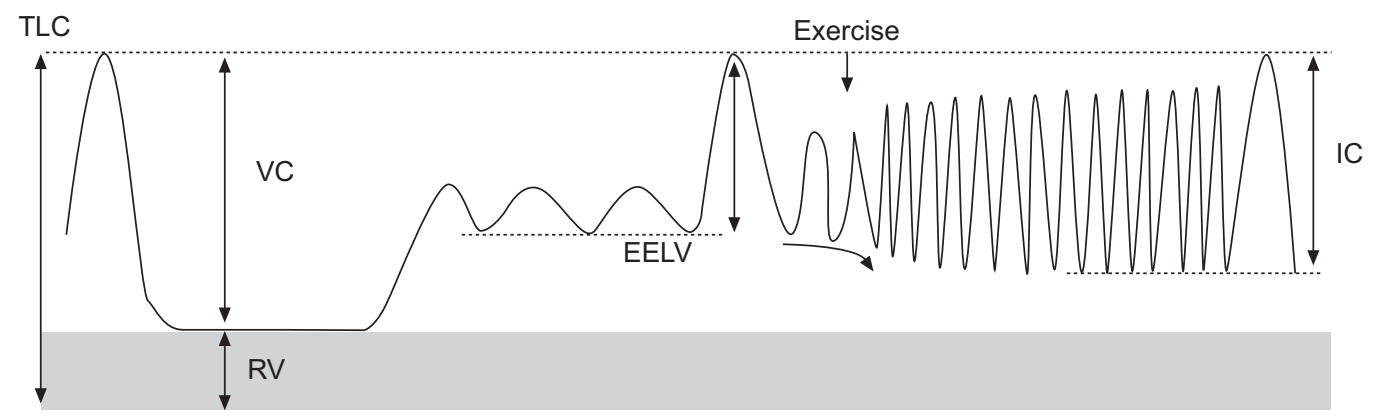

b)
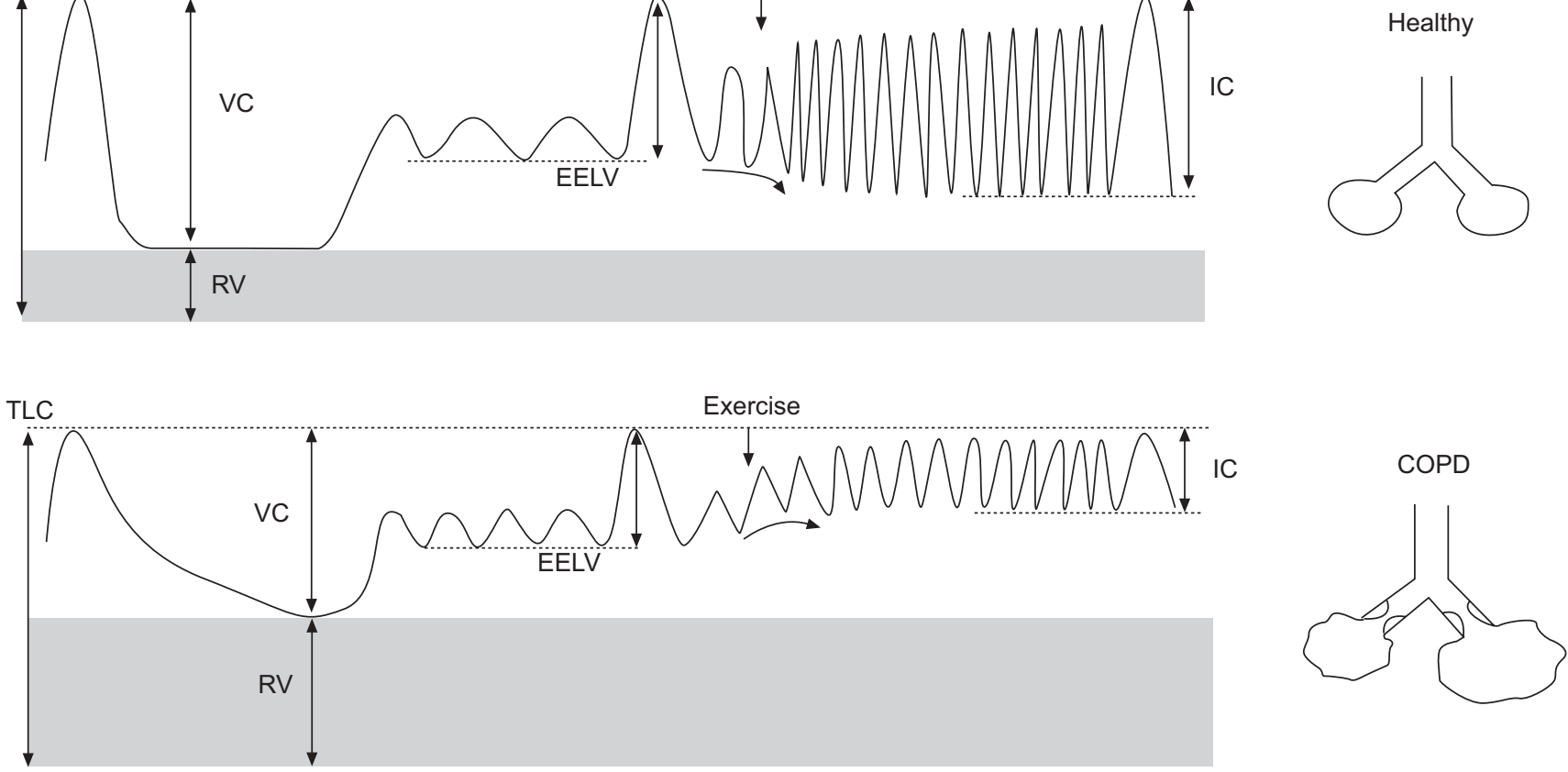

FIGURE 1. Changes in lung function with exercise in a) normal individuals versus b) patients with chronic obstructive pulmonary disease (COPD). TLC: total lung capacity; VC: vital capacity; RV: residual volume; EELV: end-expiratory lung volume; IC: inspiratory capacity. 
regular basis, relieve dyspnoea by improving dynamic airway function, thereby allowing improved lung emptying with each breath. With effective treatment, $V \mathrm{~T}$ is positioned at a lower operating lung volume (i.e. EELV is reduced, IC is increased). Therefore, patients can achieve the required alveolar ventilation during rest and exercise at a lower operating lung volume and, thus, at a lower oxygen cost of breathing. As a result, patients can exercise for longer before the mechanical limitation to ventilation (i.e. critically low IRV) is reached.

To objectively assess the effect of bronchodilator treatment on patient-centred outcomes in clinical practice, the physician needs to consider the symptoms, patient history and spirometry results together. In clinical trials, however, various approaches have been developed for the quantification of dyspnoea and exercise tolerance. One widely used instrument is the multi-dimensional Baseline Dyspnoea Index/Transition Dyspnoea Index, which assesses the impact of dyspnoea during activities of daily living. The requirement for rescue medication also provides an indication of the degree of dyspnoea experienced by the patient.

A variety of exercise-testing protocols are available, which can be categorised as "laboratory based" or "field based". Laboratory-based testing, typified by cycle ergometry, provides the most closely standardised conditions and the greatest amount of information on all of the physiological systems involved in exercise. Conversely, field-based tests are frequently used because they require less technological support and provide a test of exercise capacity that purportedly may mimic the patient's activity in daily life more closely. One widely used field-based test is the 6-min walk distance, which has also been extensively evaluated in patients with COPD.

One problem with exercise testing in the laboratory is how to translate the results into something meaningful for the patient. A potential solution is to use the oxygen cost, the value of which has been calculated for many activities [7]. These can be simulated (or reproduced) in the laboratory. For example, slow walking on a flat surface is simulated by unloaded pedalling on a cycle ergometer, shopping equates to cycle ergometry at $25 \mathrm{~W}$ and walking uphill can be reproduced by cycle ergometry at $50 \mathrm{~W}$. These correlations provide a means of translating laboratory-generated data into information about potential benefits for daily life.

\section{Tiotropium}

Tiotropium is a once-daily, long-acting anticholinergic agent with 24-h efficacy. Several large-scale, placebo-controlled clinical studies have shown that tiotropium consistently provides significant reductions in dyspnoea and improvements in exercise tolerance (table 1) [6, 8-11]. For example,

\section{TABLE 1 The effect of long-acting bronchodilators versus placebo on the management of chronic obstructive pulmonary disease in placebo-controlled trials}

\begin{tabular}{|c|c|c|c|c|c|c|}
\hline First author [ref.] & Drug & Patients n & Duration weeks & Rescue medication & Dyspnoea & Exercise \\
\hline CASABURI [8] & Tiotropium $18 \mu \mathrm{g}$ & 921 & 52 & $\uparrow$ & $\uparrow$ & NA \\
\hline Brusasco [9] & Tiotropium $18 \mu \mathrm{g}$ & 1207 & 26 & NA & $\uparrow$ & NA \\
\hline O’Donnell [6] & Tiotropium $18 \mu \mathrm{g}$ & 187 & 6 & $\uparrow$ & $\uparrow$ & $\uparrow$ \\
\hline Casaburi [10] & Tiotropium $18 \mu \mathrm{g}$ & 91 & 25 & $\uparrow^{\#}$ & $\uparrow$ & $\uparrow$ \\
\hline TONNEL [12] & Tiotropium $18 \mu \mathrm{g}$ & 554 & 36 & NA & NA & NA \\
\hline VERKINDRE [14] & Tiotropium $18 \mu \mathrm{g}$ & 100 & 12 & NA & NS & $\uparrow$ \\
\hline Dusser [15] & Tiotropium $18 \mu \mathrm{g}$ & 1010 & 52 & $\uparrow$ & NA & NA \\
\hline Boyd [16] & Salmeterol $50 \mu \mathrm{g}$ & 674 & 16 & $\uparrow$ & $\uparrow$ & NS \\
\hline JONES [17] & Salmeterol $50 \mu \mathrm{g}$ & 283 & 16 & $\uparrow$ & NA & NA \\
\hline MAHLER [18] & Salmeterol $42 \mu \mathrm{g}$ & 411 & 12 & $\uparrow$ & $\mathrm{NS}^{\#}$ & NS \\
\hline Rutten-van Mölken [19] & Salmeterol $50 \mu \mathrm{g}$ & 144 & 12 & NA & NA & NA \\
\hline MAHLER [23] & Salmeterol $50 \mu \mathrm{g}$ & 691 & 24 & $\uparrow$ & NS & NA \\
\hline Brusasco [9] & Salmeterol $50 \mu \mathrm{g}$ & 1207 & 26 & NA & $\uparrow$ & NA \\
\hline Calverley [24] & Salmeterol $50 \mu \mathrm{g}$ & 1465 & 52 & $\uparrow$ & NS & NA \\
\hline HaNANIA [25] & Salmeterol $50 \mu \mathrm{g}$ & 723 & 24 & NA & $\uparrow$ & NA \\
\hline O’DonNell [26] & Salmeterol $50 \mu \mathrm{g}$ & 23 & 2 (crossover) & NA & $\uparrow$ & $\uparrow$ \\
\hline DAHL [27] & Formoterol $12 \mu \mathrm{g}$ or $24 \mu \mathrm{g}$ & 780 & 12 & $\uparrow$ & NA & NA \\
\hline AaLBers $[28]$ & Formoterol $12 \mu \mathrm{g}$ or $24 \mu \mathrm{g}$ & 687 & 12 & $\uparrow$ & NS & NS \\
\hline Rossı [29] & Formoterol $12 \mu \mathrm{g}$ or $24 \mu \mathrm{g}$ & 854 & 52 & $\uparrow$ & NA & NA \\
\hline SZAFRANSKI [30] & Formoterol $12 \mu \mathrm{g}$ or $24 \mu \mathrm{g}$ & 812 & 52 & NM & $\mathrm{NM}^{\bullet}$ & NA \\
\hline
\end{tabular}

$\uparrow$ : significant benefit versus placebo (e.g. reduced dyspnoea, increased exercise tolerance); NA: not assessed; NS: no significant benefit versus placebo; NM: not mentioned. \#: significant benefit at weeks 2, 4, 8 and 10; ": symptom score breathlessness. 
MALTAIs et al. [11] recently compared the effects of 6 weeks' treatment with tiotropium $18 \mu \mathrm{g}$ once daily versus placebo on measures of exercise tolerance in 261 patients with severe COPD. Treatment with tiotropium resulted in significant increases in IC and IRV at rest (immediately prior to exercise) and significant increases in IC, IRV and $V$ T at isotime and at the end of exercise compared with placebo at study end (fig. 2). The reduction in lung hyperinflation at rest and during exercise with tiotropium treatment allowed for greater $V \mathrm{~T}$ expansion during exercise. Compared with placebo, tiotropium increased the constant work-rate cycle ergometry endurance time by $236 \pm 58 \mathrm{~s}(\mathrm{p}<0.001)$ at $2.25 \mathrm{~h}$ after dosing and by $171 \pm 58 \mathrm{~s}(\mathrm{p}<0.01)$ at $8 \mathrm{~h}$ after dosing at study end. Thus, treatment with tiotropium provides sustained improvements in exercise tolerance over a period of the day when patients are likely to be most active. Despite the significant increase in exercise endurance with tiotropium, there was a significant reduction in the intensity of dyspnoea at the point of symptom limitation on all test days $(\mathrm{p}<0.01$ versus placebo on days 0,21 and 42). Dyspnoea-time slopes were also decreased with tiotropium versus placebo $(\mathrm{p}<0.01$ on days 0 and $21 ; p=0.06$ on day 42 ). Thus, tiotropium meets key GOLD objectives of COPD management (i.e. relieves symptoms and improves exercise tolerance).

\section{Long-acting $\boldsymbol{\beta}_{\mathbf{2}}$-agonists}

The effect of treatment with long-acting $\beta_{2}$-agonists (LABAs), such as salmeterol and formoterol, on dyspnoea and exercise tolerance has also been extensively studied in large-scale, placebo-controlled clinical studies. Although LABAs reduced the use of rescue medication in the majority of studies, the efficacy of these agents on dyspnoea is not consistent across trials and significant benefits on exercise tolerance have not been well described (table 1) [9, 16-29]. However, a recent, small-scale (23 patients), mechanistic, crossover study showed that salmeterol significantly reduced hyperinflation, with

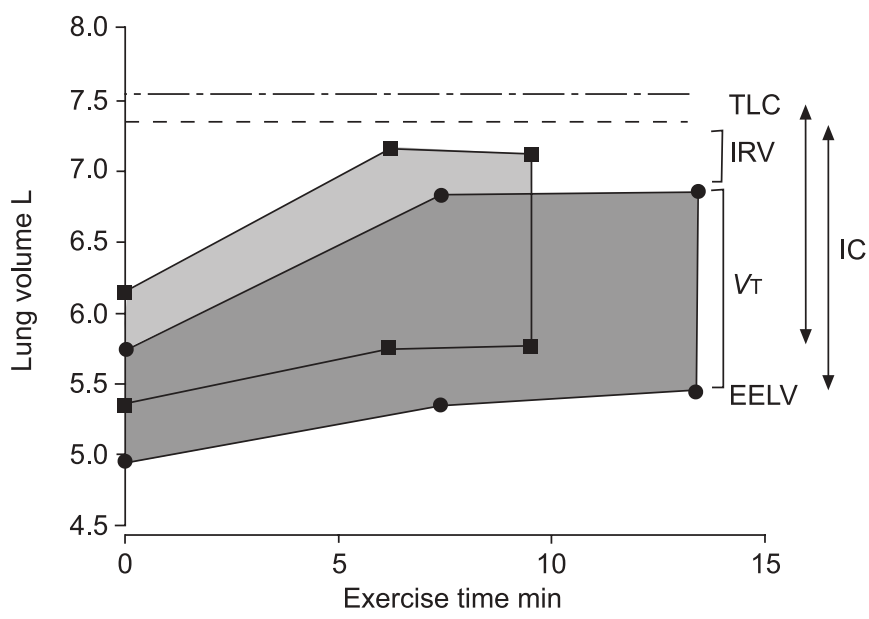

FIGURE 2. Operational lung volumes during exercise in chronic obstructive pulmonary disease patients treated with tiotropium $18 \mu \mathrm{g}(\bullet)$ versus placebo $(\mathbf{0})$ TLC: total lung capacity; IRV: inspiratory reserve volume; VT: tidal volume; IC: inspiratory capacity; EELV: end-expiratory lung volume. - - - -: TLC in the placebo group; - - - - -: TLC in the tiotropium group. Reprinted from [11] with permission from the publisher. consequent benefits in exertional dyspnoea and exercise tolerance [26]. Although dyspnoea intensity (measured using the modified Borg scale) was similar at the point of symptom limitation (somewhat severe to severe) following 2 weeks' treatment with salmeterol $50 \mu \mathrm{g}$ or placebo, patients in the salmeterol group were able to exercise for longer before reaching the same degree of dyspnoea as patients in the placebo group [26]. Compared with placebo, salmeterol increased the constant work-rate cycle ergometry endurance time by $96 \pm 36$ s $(58 \pm 19 \%)$ after 2 weeks' treatment $(p=0.018)$. The reason for this improvement was that at rest, as well as throughout exercise, IC was significantly greater and EELV was significantly reduced in the salmeterol versus the placebo group. This reduction in hyperinflation permitted patients receiving salmeterol to significantly increase $V \mathrm{~T}$ throughout exercise compared with patients in the placebo group. Dyspnoea relief during exercise was closely associated with an increased ability to expand $V \mathrm{~T}$ post-bronchodilator.

\section{Combination therapy}

The GOLD guidelines recommend optimisation of bronchodilator therapy using a combination of two long-acting bronchodilators with different pharmacological mechanisms of action in patients with moderate-to-severe COPD [1]. Such treatment may improve efficacy and decrease the risk of side-effects compared with increasing the dose of a single bronchodilator. Superior bronchodilation with combination regimens may also be accompanied by additional improvements in dyspnoea and exercise tolerance.

A recent study has shown that maintenance treatment with tiotropium combined with a LABA provided significant improvements in lung function compared with single-agent therapy [31]. Future studies should address whether the superior bronchodilation with combination regimens translates into additional improvements in patient-centred outcomes.

\section{CONCLUSIONS}

Expiratory flow limitation in patients with COPD leads to air trapping and increases in lung volume, resulting in the characteristic symptoms of COPD, such as dyspnoea, exercise intolerance and reduced HRQoL. Bronchodilator therapy relieves dyspnoea by deflating the lungs, which leads to an improvement in exercise tolerance.

Tiotropium has consistently been shown to reduce dyspnoea and improve exercise tolerance and health-related quality of life in several prospective studies of $\leqslant 1 \mathrm{yr}$ in duration. Such improvements in patient-centred outcomes may allow patients to increase their activity levels, thereby interrupting the downward spiral of chronic inactivity, leading to physical deconditioning and further reductions in exercise tolerance and health-related quality of life. From the patient's perspective, the ability to improve or resume activities of daily living is a desirable treatment goal. Sustained benefits in these patient-centred clinical parameters with tiotropium maintenance treatment over the long term could be considered as a modification of the expected clinical course of chronic obstructive pulmonary disease. To test this hypothesis, the Understanding Potential Long-term Impacts on Function with Tiotropium (UPLIFT) trial was initiated in 2003 [32]. 


\section{REFERENCES}

1 Global Initiative for Chronic Obstructive Lung Disease. Executive Summary. Updated 2005. www.goldcopd.com. Date last accessed: September 26, 2006.

2 O'Donnell DE, Bertley JC, Chau LK, Webb KA. Qualitative aspects of exertional breathlessness in chronic airflow limitation: pathophysiologic mechanisms. Am J Respir Crit Care Med 1997; 155: 109-115.

3 O'Donnell DE, Revill SM, Webb KA. Dynamic hyperinflation and exercise intolerance in chronic obstructive pulmonary disease. Am J Respir Crit Care Med 2001; 164: 770-777.

4 Di Marco F, Milic-Emili J, Boveri B, et al. Effect of inhaled bronchodilators on inspiratory capacity and dyspnoea at rest in COPD. Eur Respir J 2003; 21: 86-94.

5 Man WD, Mustfa N, Nikoletou D, et al. Effect of salmeterol on respiratory muscle activity during exercise in poorly reversible COPD. Thorax 2004; 59: 471-476.

6 O'Donnell DE, Flüge T, Gerken F, et al. Effects of tiotropium on lung hyperinflation, dyspnea and exercise tolerance in patients with COPD. Eur Respir J 2004; 23: 832-840.

7 The compendium of physical activities tracking guide. Update 2002. http://prevention.sph.sc.edu/tools/docs/ documents_compendium.pdf. Date last accessed: September 26, 2006.

8 Casaburi R, Mahler DA, Jones PW, et al. A long-term evaluation of once-daily inhaled tiotropium in chronic obstructive pulmonary disease. Eur Respir J 2002; 19: 217-224.

9 Brusasco V, Hodder R, Miravitlles M, et al. Health outcomes following treatment for six months with once daily tiotropium compared with twice daily salmeterol in patients with COPD. Thorax 2003; 58: 399-404.

10 Casaburi R, Kukafka D, Cooper CB, Witek TJ Jr, Kesten S. Improvement in exercise tolerance with the combination of tiotropium and pulmonary rehabilitation in patients with COPD. Chest 2005; 127: 809-817.

11 Maltais F, Hamilton A, Marciniuk D, et al. Improvements in symptom-limited exercise performance over $8 \mathrm{~h}$ with once-daily tiotropium in patients with COPD. Chest 2005; 128: $1168-1178$.

12 Tonnel AB, Perez T, Grosbois JM, Bravo M-L, Brun M. Improvement in HRQoL of COPD patients after 9 months treatment with tiotropium bromide: use of a new scale for daily medical practice. Eur Respir J 2005; 26: 290s.

13 Niewoehner DE, Rice K, Cote C, et al. Prevention of exacerbations of chronic obstructive pulmonary disease with tiotropium, a once-daily inhaled anticholinergic bronchodilator: a randomized trial. Ann Intern Med 2005; 143: 317-326.

14 Verkindre C, Bart F, Aguilaniu B, et al. The effect of tiotropium on hyperinflation and exercise capacity in chronic obstructive pulmonary disease. Respiration 2006; 73: 420-427.

15 Dusser D, Bravo M-L, Iacono P. The effect of tiotropium on exacerbations and airflow in patients with COPD. Eur Respir J 2006; 27: 547-555.

16 Boyd G, Morice AH, Pounsford JC, et al. An evaluation of salmeterol in the treatment of chronic obstructive pulmonary disease (COPD). Eur Respir J 1997; 10: 815-821.

17 Jones PW, Bosh TK. Quality of life changes in COPD patients treated with salmeterol. Am J Respir Crit Care Med 1997; 155: 1283-1289.
18 Mahler DA, Donohue JF, Barbee RA, et al. Efficacy of salmeterol xinafoate in the treatment of COPD. Chest 1999; 115: 957-965.

19 Rutten-van Mölken MPMH, Roos B, van Noord JA. An empirical comparison of the St George's Respiratory Questionnaire (SGRQ) and the Chronic Respiratory Disease Questionnaire (CRQ) in a clinical trial setting. Thorax 1999; 54: 995-1003.

20 van Noord JA, de Munck DRAJ, Bantje T, et al. Long-term treatment of chronic obstructive pulmonary disease with salmeterol and the additive effect of ipratropium. Eur Respir J 2000; 15: 878-885.

21 Rennard SI, Anderson W, ZuWallack R, et al. Use of a longacting inhaled $\beta_{2}$-adrenergic agonist, salmeterol xinafoate, in patients with chronic obstructive pulmonary disease. Am J Respir Crit Care Med 2001; 163: 1087-1092.

22 Chapman KR, Arvidsson P, Chuchalin AG, et al. The addition of salmeterol $50 \mu \mathrm{g}$ bid to anticholinergic treatment in patients with COPD: a randomized, placebo controlled trial. Can Respir J 2002; 9: 178-185.

23 Mahler DA, Wire P, Horstman D, et al. Effectiveness of fluticasone propionate and salmeterol combination delivered via the Diskus device in the treatment of chronic obstructive pulmonary disease. Am J Respir Crit Care Med 2002; 166: 1084-1091.

24 Calverley P, Pauwels R, Vestbo J, et al. Combined salmeterol and fluticasone in the treatment of chronic obstructive pulmonary disease: a randomised controlled trial. Lancet 2003; 361: 449-456.

25 Hanania NA, Darken P, Horstman D, et al. The efficacy and safety of fluticasone propionate $(250 \mu \mathrm{g}) /$ salmeterol $(50 \mu \mathrm{g})$ combined in the Diskus inhaler for the treatment of COPD. Chest 2003; 124: 834-843.

26 O'Donnell DE, Voduc N, Fitzpatrick M, Webb KA. Effect of salmeterol on the ventilatory response to exercise in chronic obstructive pulmonary disease. Eur Respir J 2004; 24: 86-94.

27 Dahl R, Greefhorst LAPM, Nowak D, et al. Inhaled formoterol dry powder versus ipratropium bromide in chronic obstructive pulmonary disease. Am J Respir Crit Care Med 2001; 164: 778-784.

28 Aalbers R, Ayres J, Backer V, et al. Formoterol in patients with chronic obstructive pulmonary disease: a randomized, controlled, 3-month trial. Eur Respir J 2002; 19: 936-943.

29 Rossi A, Kristufek P, Levine BE, et al. Comparison of the efficacy, tolerability, and safety of formoterol dry powder and oral, slow-release theophylline in the treatment of COPD. Chest 2002; 121: 1058-1069.

30 Szafranski W, Cukier A, Ramirez A, et al. Efficacy and safety of budesonide/formoterol in the management of chronic obstructive disease. Eur Respir J 2003; 21: 74-81.

31 van Noord JA, Aumann JL, Janssens E, et al. Comparison of tiotropium once daily, formoterol twice daily and both combined once daily in patients with COPD. Eur Respir J 2005; 26: 214-222.

32 Decramer M, Celli B, Tashkin DP, et al. Clinical trial design considerations in assessing long-term functional impacts of tiotropium in COPD: the UPLIFT trial. J COPD 2004; 1: 303-312. 